Article

\title{
Interaction between Curcumin and $\beta$-Casein: Multi-Spectroscopic and Molecular Dynamics Simulation Methods
}

\author{
Ruichen Zhao ${ }^{1,2}\left(\mathbb{D}\right.$, Xiaoli Qin ${ }^{1}(\mathbb{D})$ and Jinfeng Zhong ${ }^{1,2, *}$ \\ 1 College of Food Science, Southwest University, Chongqing 400715, China; zrchen99@foxmail.com (R.Z.); \\ qinx1@swu.edu.cn (X.Q.) \\ 2 National Demonstration Center for Experimental Food Science and Technology Education, \\ Southwest University, Chongqing 400715, China \\ * Correspondence: jinfzhong@163.com
}

Citation: Zhao, R.; Qin, X.; Zhong, J. Interaction between Curcumin and $\beta$-Casein: Multi-Spectroscopic and Molecular Dynamics Simulation Methods. Molecules 2021, 26, 5092. https: / / doi.org/10.3390/ molecules26165092

Academic Editors: Daniela Marasco and Danilo Roccatano

Received: 17 July 2021

Accepted: 19 August 2021

Published: 22 August 2021

Publisher's Note: MDPI stays neutral with regard to jurisdictional claims in published maps and institutional affiliations.

Copyright: (c) 2021 by the authors. Licensee MDPI, Basel, Switzerland. This article is an open access article distributed under the terms and conditions of the Creative Commons Attribution (CC BY) license (https:// creativecommons.org/licenses/by/ $4.0 /)$.

\begin{abstract}
Effect of temperature and $\mathrm{pH}$ on the interaction of curcumin with $\beta$-casein was explored by fluorescence spectroscopy, ultraviolet-visible spectroscopy and molecular dynamics simulation. The spectroscopic results showed that curcumin could bind to $\beta$-casein to form a complex which was driven mainly by electrostatic interaction. The intrinsic fluorescence of $\beta$-casein was quenched by curcumin through static quenching mechanism. The binding constants of curcumin to $\beta$-casein were $6.48 \times 10^{4} \mathrm{~L} / \mathrm{mol}(298 \mathrm{~K}), 6.17 \times 10^{4} \mathrm{~L} / \mathrm{mol}(305 \mathrm{~K})$ and $5.73 \times 10^{4} \mathrm{~L} / \mathrm{mol}(312 \mathrm{~K})$ at $\mathrm{pH} 2.0$, which was greater than that $\left(3.98 \times 10^{4} \mathrm{~L} / \mathrm{mol}\right.$ at $298 \mathrm{~K}, 3.90 \times 10^{4} \mathrm{~L} / \mathrm{mol}$ at $305 \mathrm{~K}$ and $3.41 \times 10^{4} \mathrm{~L} / \mathrm{mol}$ at $312 \mathrm{~K})$ at $\mathrm{pH}$ 7.4. Molecular docking study showed that binding energy of $\beta$-casein-curcumin complex at pH $2.0(-7.53 \mathrm{kcal} / \mathrm{mol})$ was lower than that at $\mathrm{pH} 7.4(-7.01 \mathrm{kcal} / \mathrm{mol})$. The molecular dynamics simulation study showed that the binding energy $(-131.07 \mathrm{~kJ} / \mathrm{mol})$ of $\beta$-casein-curcumin complex was relatively low at pH 2.0 and $298 \mathrm{~K}$. $\alpha$-Helix content in $\beta$-casein was decreased and random coil content was increased in the presence of curcumin. These results can promote a deep understanding of interaction between curcumin and $\beta$-casein and provide a reference for improving the bioavailability of curcumin.
\end{abstract}

Keywords: hydrophobic interaction; fluorescence quenching; molecular docking; secondary structure content; thermodynamic parameters

\section{Introduction}

Curcumin is a natural polyphenol compound derived from turmeric, and commonly used as a natural colorant [1]. Compared with artificial synthetic food additives, curcumin is nontoxic [2] and has anti-inflammatory [3], antibacterial [4], anti-cancer [5], and antioxidant [6] effects. However, curcumin has poor water solubility, low bioavailability and tends to degrade at neutral and basic conditions, limiting its use in functional foods. For example, intestinal epithelial cells can only absorb soluble curcumin, and insoluble curcumin will be excreted in feces. Therefore, the water solubility of curcumin needs to be increased to improve its absorption in the gut [7]. Studies have found that protein can act as an affinity binding agent for polyphenols and may be an ideal carrier for curcumin and other small molecules. Michele et al. [8] added powdered curcumin to buttermilk and increased the bioavailability of curcumin 15 times. Another study found that encapsulating curcumin in $\beta$-casein could increase the solubility of curcumin by 2500 times, and the binding of these two compounds increased the antioxidant effects of curcumin [9]. These studies showed that it was feasible to use protein to improve the solubility and bioavailability of curcumin. However, the interaction between curcumin and protein is unclear.

The binding of curcumin to protein can be studied by fluorescence spectroscopy, ultraviolet-visible spectroscopy, circular dichroism and in silico approaches. Molecular 
dynamics (MD) simulation is a powerful in silico method that uses computers to simulate protein structure and dynamics modeling, which provides detailed information on protein conformational changes and fluctuations [10]. It helps us to understand related experimental phenomena and mechanism. Rajabi et al. [11] found that the conformation of trypsin was changed and unstable when curcumin bound to the it by MD simulation. At the same time, they found that curcumin and trypsin formed a complex mainly driven by hydrogen bond and van der Waals interaction by spectral experiment and MD simulation. Zhang et al. [10] found that hydrophobic interaction and hydrogen bond promoted the myosin-curcumin complex by MD simulation, and they found that the quenching mechanism of curcumin on myosin was static quenching by spectral experiment, which was beneficial to the formation of myosin-curcumin complex. Wang et al. [12] found that there was face-to-face $\pi-\pi$ stacking between the tryptophan of nucleocapsid proteins and the aromatic rings of curcumin.

However, little information is available about the influence of $\mathrm{pH}$ and temperature on the stability of casein-curcumin complex. The protein structure can be affected by environmental stresses such as temperature and $\mathrm{pH}$ [13]. In turn, changes in the protein structure may be related to changes of the stability between the protein and the curcumin, which may alter the performances of curcumin in delivery systems. Therefore, it is important to understand the effect of temperature and $\mathrm{pH}$ on the interaction between curcumin and protein.

Previous studies have shown that human serum albumin [14], bovine serum albumin [15], $\beta$-lactoglobulin [16], and soy protein isolate [17] could be used as carriers for curcumin. Casein is one of the main proteins in milk [18] and has high nutritional value, good sensory properties, and lower cost. The structural characteristics of casein give it many functional properties, including the combination with ions and small molecules, good surface activity, stability, and gel forming properties. These properties, combined with its high nutritional value, make casein highly sought after in the food industry. For example, Zhang et al. [19] found that exopolysaccharide and casein formed a complex mainly driven by intermolecular hydrogen bond, hydrophobic and electrostatic contacts by infrared spectroscopy. Qin et al. [20] found that caffeic acid and caffeic acid phenethyl ester bound to micellar casein via hydrophobic interactions, and the presence of complexes was confirmed by X-ray diffraction and Fourier transform infrared spectroscopy. However, few reports are available on the interactions between casein and curcumin.

In this paper, spectroscopy was used to study the interactions between curcumin and casein under different temperatures and $\mathrm{pH}$ conditions. Furthermore, molecular docking and MD simulation were used to further examine the interactions between $\beta$-casein and curcumin at the molecular scale, which was expected to provide a theoretical basis for the widespread use of casein and curcumin complexes in the food industry.

\section{Results}

\subsection{Fluorescence Spectra}

The endogenous fluorescence of casein comes from tryptophan (Trp), tyrosine (Tyr), and phenylalanine (Phe). The fluorescence information of these amino acids is usually used to study the conformational changes of proteins caused by ligands [21]. Figure 1 shows the effects of curcumin concentration on the fluorescence spectra of casein at $298 \mathrm{~K}$. The fluorescence peak of casein appeared around $337 \mathrm{~nm}$ at $\mathrm{pH}$ 7.4. In contrast, a fluorescence peak appeared around $334 \mathrm{~nm}$ at $\mathrm{pH}$ 2.0. As curcumin concentration increased, the fluorescence intensity gradually decreased, indicating an interaction between casein and curcumin. 

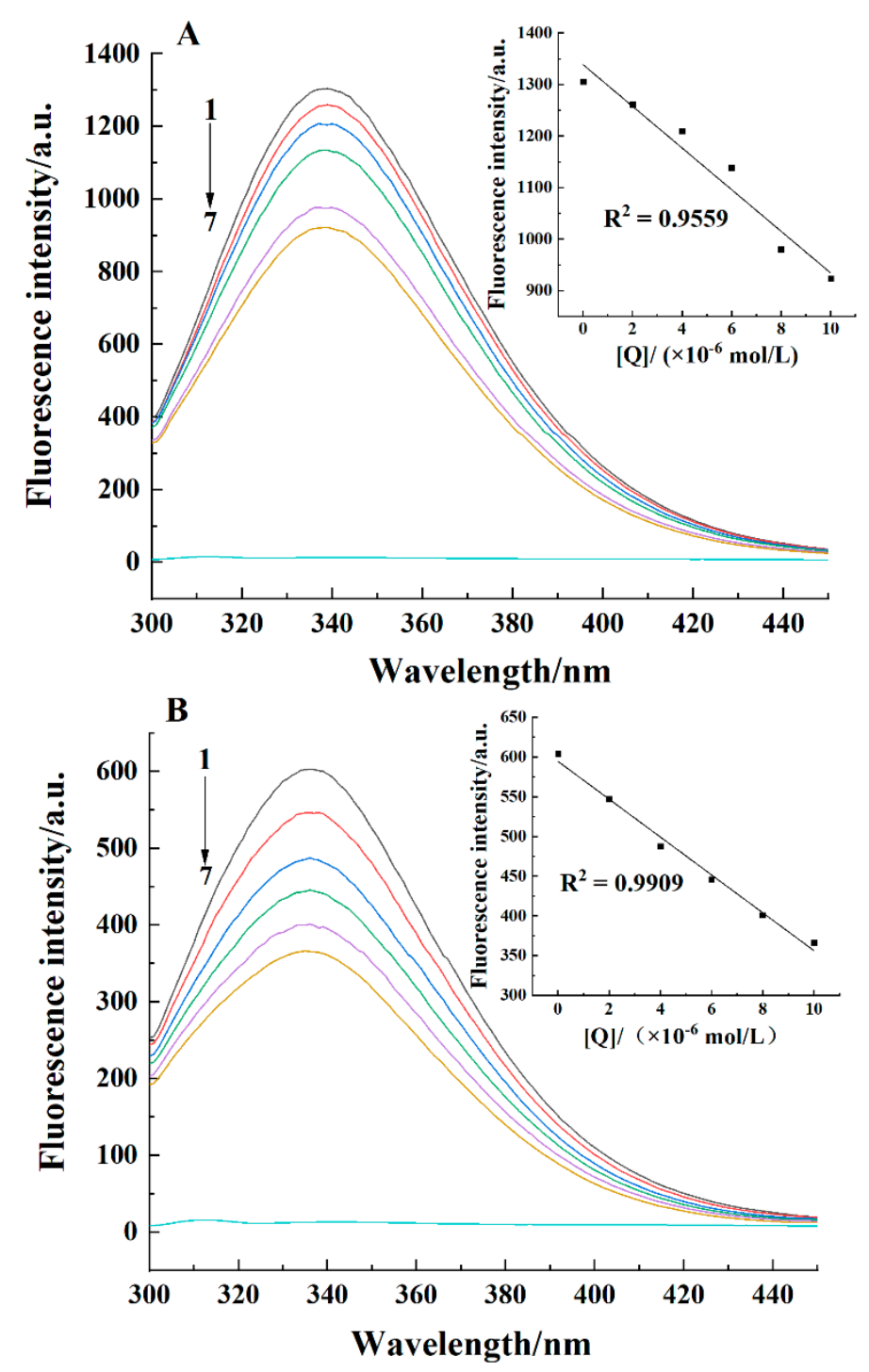

Figure 1. Fluorescence spectra of casein in the absence and presence of curcumin at $298 \mathrm{~K}$ at $\mathrm{pH} 7.4$ (A) and pH 2.0 (B). The curcumin concentrations in curves $1-6$ were $0 \times 10^{-6}, 2 \times 10^{-6}$, $4 \times 10^{-6}, 6 \times 10^{-6}, 8 \times 10^{-6}$, and $10 \times 10^{-6} \mathrm{~mol} / \mathrm{L}$. Curve 7 was for $0.05 \mathrm{~mol} / \mathrm{L}$ Tris-HCl buffer. Casein concentration was $0.2 \mathrm{~g} / \mathrm{L}$.

The effect of $\mathrm{pH}$ and temperature on the binding and thermodynamic parameters of casein-curcumin complex is listed in Table $1 . K_{s v}$ at $\mathrm{pH} 2.0$ was approximately 1.5 times as high as that at $\mathrm{pH} 7.4$, indicating that the complex was more stable at $\mathrm{pH} 2.0$. In addition, $K_{s v}$ values at both $\mathrm{pH}$ values were decreased with increasing temperature, indicating that the complex was more stable at low temperature. The $K_{q}$ values under the two $\mathrm{pH}$ conditions were greater than the maximum diffusion collision quenching constant $\left(2.0 \times 10^{10} \mathrm{~L} /(\mathrm{mol} \cdot \mathrm{s})\right)$ [22], demonstrating that the quenching mechanism of casein by curcumin was static quenching [23]. The magnitude of $K_{b}$ was in the range of $10^{4}$, demonstrating that the binding of curcumin to casein was strong. Moreover, $K_{b}$ was relatively large at $\mathrm{pH} 2.0$, indicating that curcumin had a relatively great ability to bind to casein at $\mathrm{pH}$ 2.0. $K_{b}$ decreased as temperature increased, showing that low temperature favored the binding of curcumin to casein. The number of binding sites was approximately 1 , showing that curcumin and casein could form a complex at a molar ratio of 1:1. 
Table 1. Binding and thermodynamic parameters of casein-curcumin complex at different $\mathrm{pH}$ values and temperatures.

\begin{tabular}{|c|c|c|c|c|c|c|c|c|}
\hline pH & $T / K$ & $\begin{array}{c}K_{s v} \times 10^{4} \\
/(\mathrm{L} / \mathrm{mol})\end{array}$ & $\begin{array}{c}K_{q} \times 10^{12} \\
/(\mathrm{L} /(\mathrm{mol} \cdot \mathrm{s}))\end{array}$ & $n$ & $\begin{array}{c}K_{b} \times 10^{4} \\
/(\mathrm{L} / \mathrm{mol})\end{array}$ & $\Delta H /(\mathrm{kJ} / \mathrm{mol})$ & $\Delta S /(\mathrm{J} /(\mathrm{mol} \cdot \mathrm{K}))$ & $\Delta G /(\mathrm{kJ} / \mathrm{mol})$ \\
\hline \multirow[t]{3}{*}{7.4} & 298 & $3.67 \pm 0.19$ & $3.67 \pm 0.19$ & $1.59 \pm 0.14$ & $3.98 \pm 0.26$ & $-8.43 \pm 0.10$ & $59.93 \pm 0.28$ & $-17.87 \pm 0.09$ \\
\hline & 305 & $3.49 \pm 0.07$ & $3.49 \pm 0.07$ & $1.35 \pm 0.08$ & $3.90 \pm 0.15$ & $-8.43 \pm 0.10$ & $59.93 \pm 0.28$ & $-18.29 \pm 0.10$ \\
\hline & 312 & $3.42 \pm 0.07$ & $3.42 \pm 0.07$ & $1.01 \pm 0.01$ & $3.41 \pm 0.06$ & $-8.43 \pm 0.10$ & $59.93 \pm 0.28$ & $-18.71 \pm 0.09$ \\
\hline \multirow[t]{3}{*}{2.0} & 298 & $6.28 \pm 0.05$ & $6.28 \pm 0.05$ & $1.13 \pm 0.02$ & $6.48 \pm 0.03$ & $-6.84 \pm 0.11$ & $69.21 \pm 0.40$ & $-20.63 \pm 0.12$ \\
\hline & 305 & $5.98 \pm 0.09$ & $5.98 \pm 0.09$ & $1.17 \pm 0.05$ & $6.17 \pm 0.05$ & $-6.84 \pm 0.11$ & $69.21 \pm 0.40$ & $-21.12 \pm 0.12$ \\
\hline & 312 & $5.74 \pm 0.09$ & $5.74 \pm 0.09$ & $1.07 \pm 0.07$ & $5.73 \pm 0.03$ & $-6.84 \pm 0.11$ & $69.21 \pm 0.40$ & $-21.60 \pm 0.12$ \\
\hline
\end{tabular}

Thermodynamic parameters can be used to judge the main interaction involved in the interaction between curcumin and casein. $\Delta H<0$ and $\Delta S>0$ demonstrated that the binding of curcumin to casein was mainly driven by electrostatic interaction [24]. $\Delta H<0$ indicated that the reaction was exothermic, which also corresponded to the reduction of the binding constant with the increase of temperature. Also, $\Delta G<0$ showed that this binding was spontaneous.

\subsection{Ultraviolet-Visible Spectra}

The ultraviolet-visible spectroscopy is used to get the information about the structural change of proteins [25]. The chromophores of proteins (the aromatic amino acids)particularly tryptophan-displayed absorption peak around $280 \mathrm{~nm}$ [26]. In addition, the $\alpha$-helical structure also had a characteristic absorption peak around $210 \mathrm{~nm}$, which could roughly determine the binding position of curcumin. Figure 2 shows the effect of curcumin concentration on the ultraviolet-visible spectra of casein. Two absorption peaks could be seen at 210 and $280 \mathrm{~nm}$. The absorbance value increased as curcumin concentration increased, indicating that there were interactions between curcumin and casein, but the peak position remained the same at all curcumin concentrations. This was similar to the result of Cao et al. [21] who studied the effect of eriocitrin concentration on the ultraviolet-visible spectra of $\beta$-casein. Significant changes in the spectra occurred before and after curcumin was added, confirming that the quenching mechanism of casein fluorescence by curcumin was static quenching.

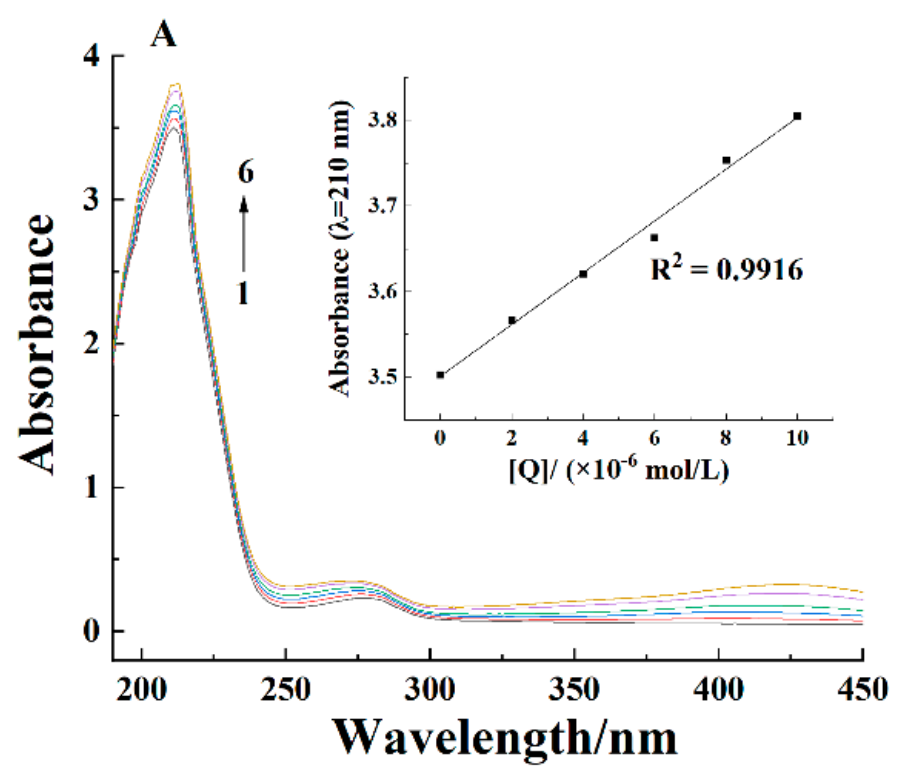

Figure 2. Cont. 


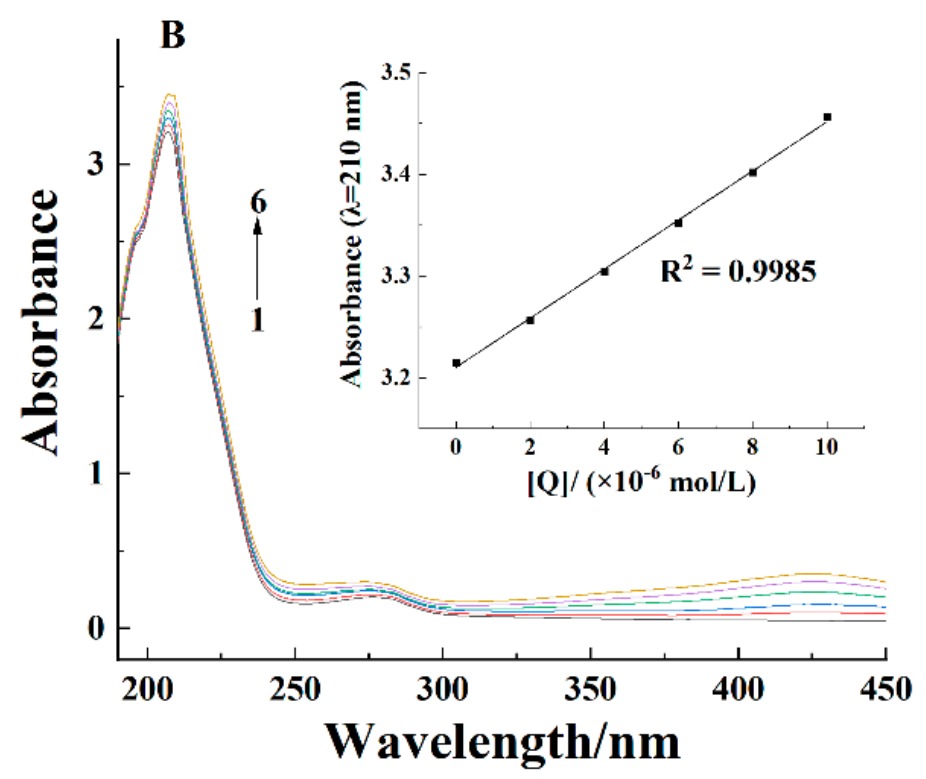

Figure 2. Ultraviolet-visible spectra of casein in the absence and presence of curcumin at $298 \mathrm{~K}$ at $\mathrm{pH} 7.4$ (A) and $\mathrm{pH} 2.0$ (B). The curcumin concentrations in curves $1-6$ were $0 \times 10^{-6}, 2 \times 10^{-6}$, $4 \times 10^{-6}, 6 \times 10^{-6}, 8 \times 10^{-6}$, and $10 \times 10^{-6} \mathrm{~mol} / \mathrm{L}$. Casein concentration was $0.2 \mathrm{~g} / \mathrm{L}$.

\subsection{Homology Modeling and Evaluation of Three-Dimensional Structure of $\beta$-Casein}

Casein is a complex of four kinds of proteins, including $\alpha_{\mathrm{s} 1}$-casein, $\alpha_{\mathrm{s} 2}$-casein, $\beta$ casein, and $\mathrm{k}$-casein. $\beta$-Casein accounts for more than $25 \%$ of the total protein content in milk. Therefore, $\beta$-casein is chosen for modeling and subsequent analysis. The PROCHECK program is used to assess the model obtained (Figure 3A) and to generate its Ramachandran plot (Figure 3B). As shown in Figure 3B, black (or red) blocks represent residues; red regions represent optimal regions; bright yellow regions represent rational regions; pale-yellow reasons represent rational regions, and white regions are prohibited regions. $81.6 \%$ amino acids were in the optimal region, $15.1 \%$ amino acids were in the additional allowed regions, $1.1 \%$ amino acids were in the generously allowed regions, and only $2.2 \%$ amino acids were in the disallowed regions, which showed that the skeletal construction of the $\beta$-casein was reliable.

A

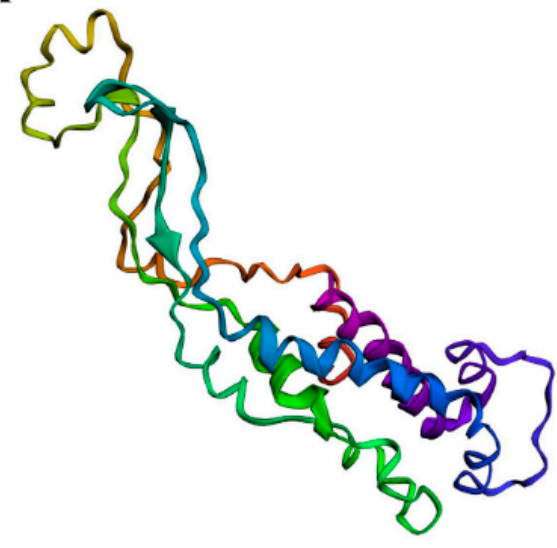

B

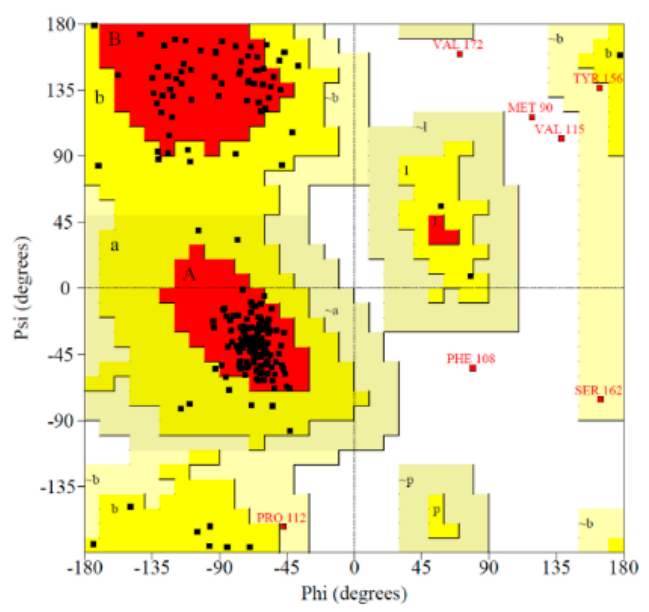

Figure 3. $\beta$-casein model (A) and its Ramachandran plot (B).

\subsection{Molecular Docking}

Molecular docking can be used to study the binding site of ligand and receptor. Table 2 shows the binding energy $\left(E_{b}\right)$ and dissociation constant $\left(K_{d}\right)$ obtained from docking results. 
The greater $K_{d}$, the higher was the associated $E_{b}$, but the relationship $\left(E_{b}\right.$ vs. $\left.K_{d}\right)$ was nonlinear, emerging as a monotonically increasing trend. $E_{b}$ at $\mathrm{pH} 2.0(-7.53 \mathrm{kcal} / \mathrm{mol})$ was lower than that at $\mathrm{pH} 7.4(-7.01 \mathrm{kcal} / \mathrm{mol})$, indicating that the binding of curcumin to $\beta$-casein at $\mathrm{pH} 2.0$ was relatively strong. These results agreed with those obtained from the fluorescence spectroscopy experiment (Table 1), in which $K_{b}$ at $\mathrm{pH} 2.0$ was greater than that at $\mathrm{pH} 7.4$.

Table 2. Binding energy and dissociation conformation of all conformations obtained by docking of curcumin to $\beta$-casein.

\begin{tabular}{|c|c|c|c|c|}
\hline pH & Conformation & $E_{b} /(\mathrm{kcal} / \mathrm{mol})$ & $K_{d} /\left(\times 10^{-7} \mathrm{~mol} / \mathrm{L}\right)$ & Present Interacting Receptor Residues \\
\hline \multirow[t]{9}{*}{7.4} & 1 & -7.01 & 0.73 & 10 \\
\hline & 2 & -6.42 & 1.90 & 11 \\
\hline & 3 & -6.38 & 2.10 & 10 \\
\hline & 4 & -6.34 & 2.20 & 11 \\
\hline & 5 & -6.15 & 3.10 & 6 \\
\hline & 6 & -6.08 & 3.50 & 7 \\
\hline & 7 & -5.67 & 7.10 & 10 \\
\hline & 8 & -5.58 & 8.20 & 9 \\
\hline & 9 & -5.54 & 8.70 & 9 \\
\hline \multirow[t]{8}{*}{2.0} & 1 & -7.53 & 0.30 & 11 \\
\hline & 2 & -7.17 & 0.55 & 9 \\
\hline & 3 & -6.79 & 1.00 & 10 \\
\hline & 4 & -6.62 & 1.40 & 12 \\
\hline & 5 & -6.10 & 3.40 & 7 \\
\hline & 6 & -5.94 & 4.50 & 8 \\
\hline & 7 & -5.89 & 4.90 & 8 \\
\hline & 8 & -5.72 & 6.40 & 9 \\
\hline
\end{tabular}

Figure 4A-E show the visualization results of the conformation with the lowest energy that are obtained from docking of curcumin to $\beta$-casein. Figure $4 \mathrm{C}, \mathrm{F}$ shows the type of interaction between various amino acids residues and curcumin (only short-distance interactions were shown). At pH 7.4, there were hydrophobic interactions between curcumin and Glu 61, Pro 64, Tyr 65, Thr 67, Leu 68, Asn 71, Lys 113, and Pro 136. At pH 2.0, there were hydrophobic interactions between curcumin and Glu 4, Gln 5, Val 8, Tyr 65, Pro 66, Pro 69, and Gln 70. However, other existing interactions could not be excluded due to the complexity of $\beta$-casein structure and the limitations of LigPlot software.

\subsection{Simulation}

MD simulation can be used to study the dynamics properties and stability of the docked complex of curcumin and $\beta$-casein.

\subsubsection{Analysis of the RMSD Value}

The trajectory stability is checked by the analysis of the RMSD value as functions of time for $\beta$-casein and its complexes with curcumin. Figure 5 shows the changes in the backbone RMSD values of $\beta$-casein with time under different $p H$ values. At 298 and $333 \mathrm{~K}$, the final RMSD values of $\beta$-casein at $\mathrm{pH} 7.4$ were stable at around $11 \AA$ (after $50 \mathrm{~ns}$ ) and $17 \AA$ (after $48 \mathrm{~ns}$ ), whereas the values for the $\beta$-casein-curcumin complex were stable at around $9 \AA$ (after $17 \mathrm{~ns}$ ) and $12 \AA$ (after $30 \mathrm{~ns}$ ). At pH 2.0, $\beta$-casein was stable at around $10.5 \AA$ (after $34 \mathrm{~ns}$ ) and $9 \AA$ (after $50 \mathrm{~ns}$ ), while the $\beta$-casein-curcumin complex was stable at around $8.5 \AA$ (after $7 \mathrm{~ns}$ ) and $11.5 \AA$ (after $45 \mathrm{~ns}$ ). It could be seen that the RMSD of the complex was lower than that of $\beta$-casein under the same condition (except at $\mathrm{pH} 2.0$ and $333 \mathrm{~K}$ ), which suggested that the structure of $\beta$-casein was more stable in the presence of curcumin. As temperature increased, the fluctuation of RMSD increased, and the final stable RMSD value also increased. On the other hand, the fluctuation of RMSD of $\beta$-caseincurcumin complex at $\mathrm{pH} 2.0$ was significantly lower than that at $\mathrm{pH} 7.4$, indicating that the structure of complex was relatively stable at $\mathrm{pH}$ 2.0. The fluctuation of RMSD of the 
complex before stabilization might be caused by curcumin entering the hydrophobic space of $\beta$-casein. During this process, the system changed from an ordered state to a disorderly state, the structure also became looser, being consistent with $\Delta S>0$ obtained from the fluorescence quenching experiment (Table 1). In summary, the RMSD curve of the complex reached a relatively stable value with low fluctuation at $\mathrm{pH} 2.0$ and $298 \mathrm{~K}$, suggesting that the complex was the most stable at this condition.

\section{pH 7.4}

\section{pH 2.0}

D
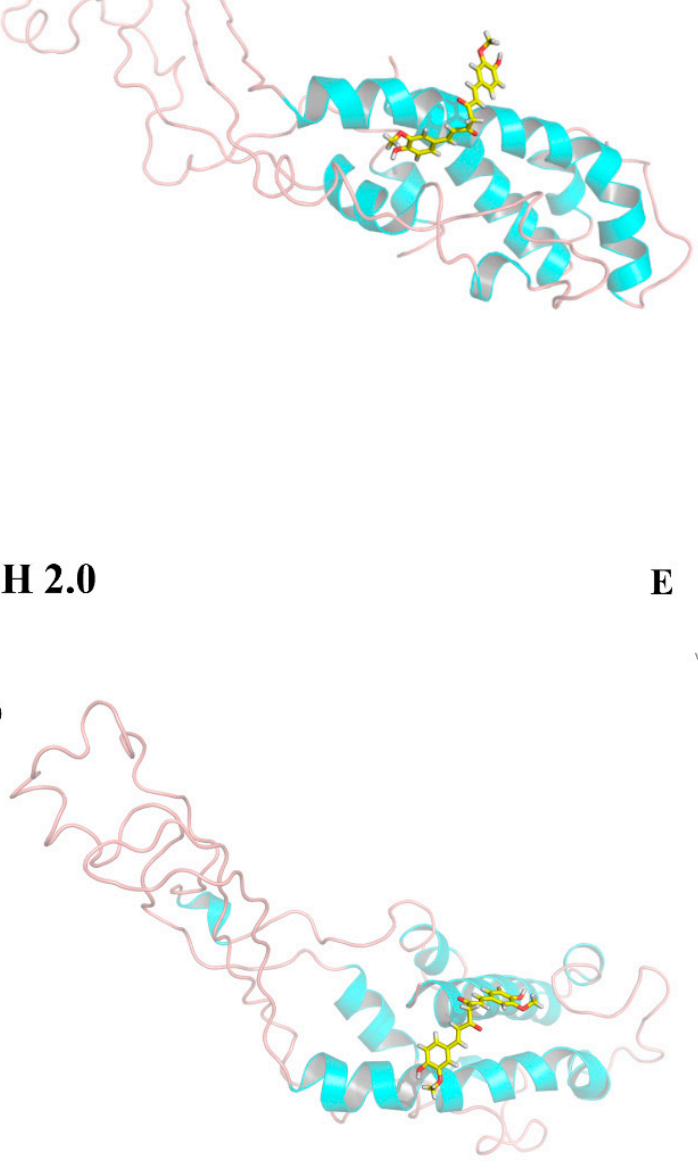

$\mathbf{E}$
B
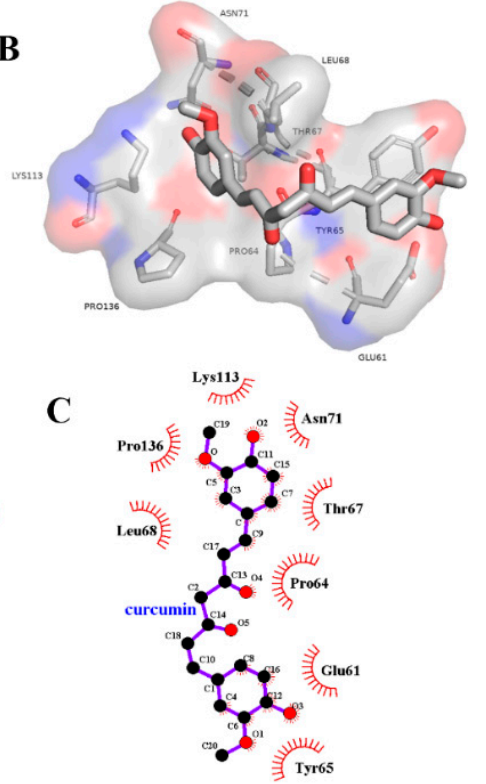
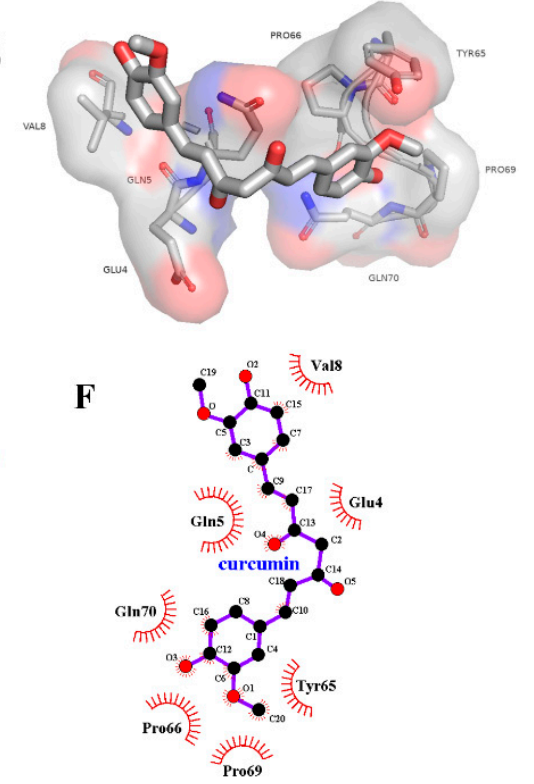

Figure 4. 3D image of the best binding pose for curcumin docked into the $\beta$-casein at $\mathrm{pH} 7.4$ (A) and $\mathrm{pH} 2.0(\mathrm{D}), 3 \mathrm{D}$ characterization of the interacted residues between curcumin and $\beta$-casein at $\mathrm{pH} 7.4(\mathbf{B})$ and $\mathrm{pH} 2.0(\mathbf{E})$, and 2D characterization of the interacted residues between curcumin and $\beta$-casein at $\mathrm{pH} 7.4(\mathbf{C})$ and $\mathrm{pH} 2.0(\mathbf{F})$. 

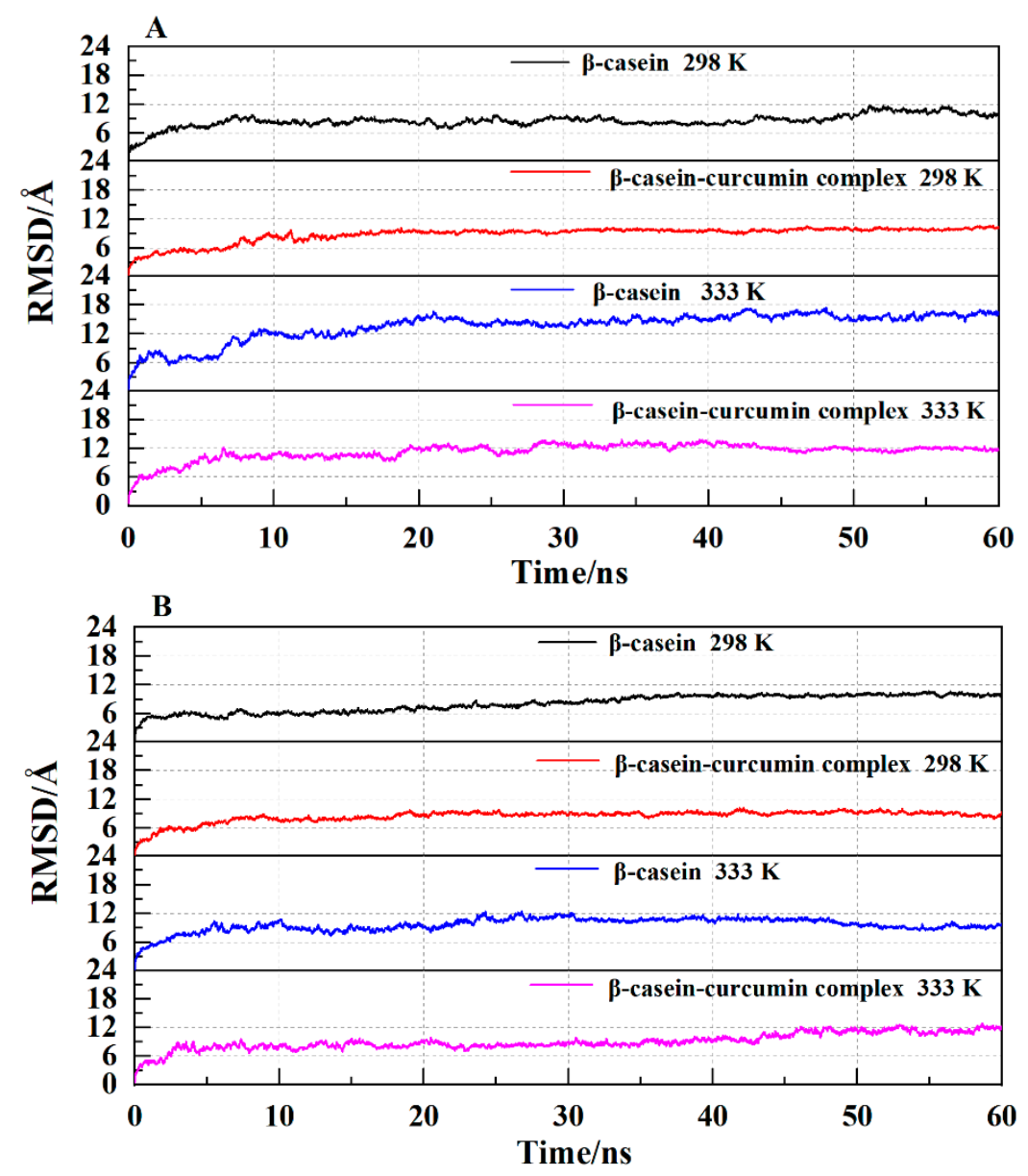

Figure 5. The backbone RMSD of $\beta$-casein in the absence/presence of curcumin at $\mathrm{pH} 7.4$ (A) and pH 2.0 (B).

\subsubsection{Hydrogen Bond Analysis}

Figure 6 shows the changes in the number of hydrogen bonds in the simulation system with time. The system had a maximum of four hydrogen bonds at $\mathrm{pH} 2.0$ and $333 \mathrm{~K}$, but 0 or 1 hydrogen bond occurred in the system most of the time. Moments where hydrogen bonds had been disappeared were hypothesized to be driven by other interactions. At the same $\mathrm{pH}$, the frequency of hydrogen bonds occurrence significantly increased in the system as temperature increased. At the same temperature, the number of hydrogen bonds and the occurrence frequencies of hydrogen bonds in the system increased at $\mathrm{pH} 2.0$ compared with $\mathrm{pH} 7.4$.

\subsubsection{System Energy Analysis}

Table 3 shows a summary of various energy items in the system during the last $15 \mathrm{~ns}$ MD simulation. $\Delta E, \Delta E_{v d w}, \Delta E_{\text {elec }}$ and $\Delta E_{\text {inter }}$ represented the total energy of the system, the energy of van der Waals force, electrostatic energy and internal energy, respectively. $\Delta E$ was the sum of $\Delta E_{v d w}, \Delta E_{\text {elec }}$ and $\Delta E_{\text {inter }}$. The contribution of $\Delta E_{v d w}$ and $\Delta E_{\text {inter }}$ to $\Delta E$ was relatively small, and their positive values were not conducive to the stability of the system. $\Delta E_{\text {elec }}$ accounted for a large proportion of the total energy and was a negative value, which was conducive to the stability of the system. It showed that the electrostatic interaction dominated the binding of curcumin to $\beta$-casein. This was consistent with the result obtained in Table 1 that the binding of curcumin to casein was mainly driven by electrostatic interaction. 

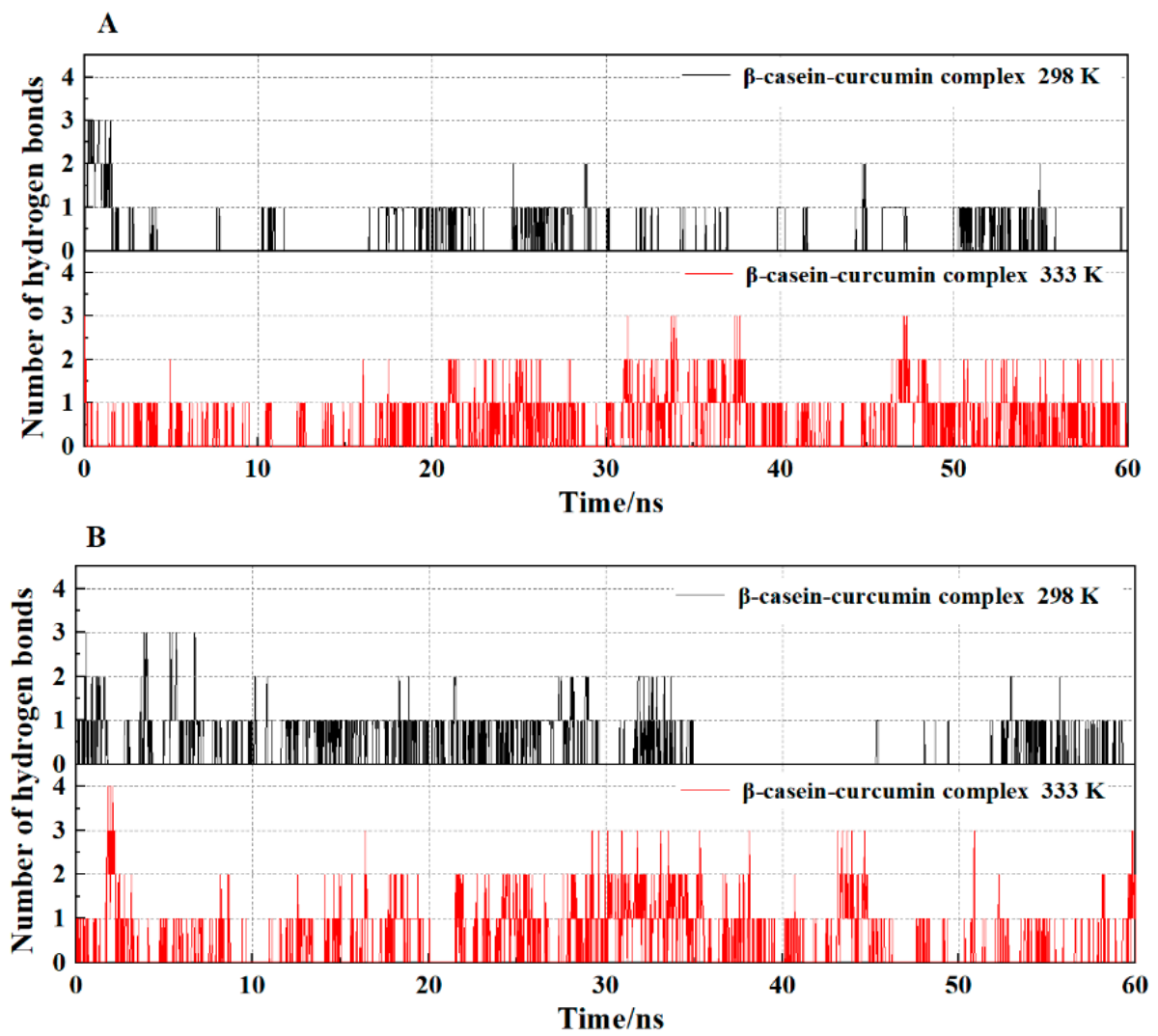

Figure 6. The effects of temperature on the number of hydrogen bonds of $\beta$-casein-curcumin complex during $60 \mathrm{~ns} \mathrm{MD}$ simulation at $\mathrm{pH} 7.4$ (A) and $\mathrm{pH} 2.0$ (B).

Table 3. Various energy items in the system.

\begin{tabular}{|c|c|c|c|c|c|c|c|c|c|}
\hline \multirow{2}{*}{$\mathrm{pH}$} & \multirow{2}{*}{$T / \mathrm{K}$} & \multirow{2}{*}{$\begin{array}{c}\Delta E_{v d w} / \\
(\mathrm{kJ} / \mathrm{mol})\end{array}$} & \multirow{2}{*}{$\begin{array}{c}\Delta E_{\text {elec }}{ }^{\prime} \\
(\mathrm{kJ} / \mathrm{mol})\end{array}$} & \multicolumn{4}{|c|}{$\Delta E_{\text {inter }} /(\mathrm{kJ} / \mathrm{mol})$} & \multirow{2}{*}{$\begin{array}{c}\Delta E / \\
(\mathbf{k J} / \mathrm{mol})\end{array}$} & \multirow{2}{*}{$\begin{array}{c}E_{\text {bind }} l \\
(\mathrm{~kJ} / \mathrm{mol})\end{array}$} \\
\hline & & & & $\Delta E_{\text {bond }}$ & $\Delta E_{\text {angle }}$ & $\Delta E_{\text {dihedral }}$ & $\Delta E_{\text {planarity }}$ & & \\
\hline \multirow[t]{2}{*}{7.4} & 298 & $2.14 \times 10^{5}$ & $-1.61 \times 10^{6}$ & $1.04 \times 10^{5}$ & $5.69 \times 10^{4}$ & $5.22 \times 10^{4}$ & 397.52 & $-1.18 \times 10^{6}$ & -88.85 \\
\hline & 333 & $2.33 \times 10^{5}$ & $-1.78 \times 10^{6}$ & $1.29 \times 10^{5}$ & $6.97 \times 10^{4}$ & $5.29 \times 10^{4}$ & 440.38 & $-1.30 \times 10^{6}$ & -35.70 \\
\hline \multirow[t]{2}{*}{2.0} & 298 & $3.36 \times 10^{5}$ & $-2.44 \times 10^{6}$ & $1.59 \times 10^{5}$ & $8.40 \times 10^{4}$ & $5.08 \times 10^{4}$ & 398.18 & $-1.81 \times 10^{6}$ & -131.07 \\
\hline & 333 & $2.58 \times 10^{5}$ & $-1.95 \times 10^{6}$ & $1.42 \times 10^{5}$ & $7.63 \times 10^{4}$ & $5.11 \times 10^{4}$ & 445.60 & $-1.42 \times 10^{6}$ & -79.28 \\
\hline
\end{tabular}

$E_{\text {bind }}$ represents the binding energy after the system reached equilibrium between curcumin and casein. Table 3 shows the average values of binding energy calculated over the last $15 \mathrm{~ns}$ MD simulated stable trajectory. At the same temperature, $E_{\text {bind }}$ at $\mathrm{pH} 2.0$ was lower than that at $\mathrm{pH} 7.4$, indicating that the complex was more stable at $\mathrm{pH} 2.0$, which was also consistent with those obtained from the spectroscopic experiment $\left(K_{s v}\right.$ and $K_{b}$ values at $\mathrm{pH} 2.0$ were all greater than those at $\mathrm{pH} 7.4$ in Table 1). As the temperature increased, the binding energy increased. The complex was more stable at $\mathrm{pH} 2.0$ and $298 \mathrm{~K}$ than at other conditions.

\subsubsection{Analysis of Secondary Structure Content}

As shown in Table 4, the presence of curcumin resulted in relatively large changes in the contents of $\alpha$-helix and coil of $\beta$-casein compared with $\beta$-sheet and turn contents. The complex showed a decrease in $\alpha$-helix content and an increase in random coil content compared to $\beta$-casein, and the greatest change in secondary structure content was observed at $\mathrm{pH} 2.0$ and $298 \mathrm{~K}$. As temperature increased, $\alpha$-helix content in the complex increased by $3.66 \%$ at $\mathrm{pH} 7.4$ and $4.49 \%$ at $\mathrm{pH} 2.0$, respectively. The $\alpha$-helix content of the complex increased by $4.13 \%$ at $298 \mathrm{~K}$ and $4.96 \%$ at $333 \mathrm{~K}$ when $\mathrm{pH}$ changed from 7.4 to 2.0 . These results suggested that the secondary structure of $\beta$-casein was affected by temperature 
and $\mathrm{pH}$. Combined with the results of hydrogen bond analysis, it was speculated that an increase in temperature or a decrease in $\mathrm{pH}$ would promote the formation of hydrogen bonds in the chain (Figure 6), thereby increasing $\alpha$-helix content.

Table 4. Effect of temperature and $\mathrm{pH}$ on the composition of secondary structure of $\beta$-casein and $\beta$-casein-curcumin complex.

\begin{tabular}{|c|c|c|c|c|c|c|}
\hline & $\mathrm{pH}$ & $T / \mathrm{K}$ & $\begin{array}{c}\alpha-\text { Helix } \\
\text { Content/\% }\end{array}$ & $\begin{array}{c}\beta-S h e e t \\
\text { Content } / \%\end{array}$ & $\begin{array}{c}\text { Turn } \\
\text { Content } / \%\end{array}$ & $\begin{array}{c}\text { Random Coil } \\
\text { Content } / \%\end{array}$ \\
\hline \multirow[t]{4}{*}{$\beta$-Casein } & 7.4 & 298 & 21.47 & 4.10 & 20.11 & 50.72 \\
\hline & & 333 & 21.93 & 5.57 & 21.56 & 47.18 \\
\hline & 2.0 & 298 & 26.27 & 1.63 & 17.75 & 51.89 \\
\hline & & 333 & 27.29 & 1.83 & 21.74 & 46.81 \\
\hline \multirow[t]{4}{*}{ Complex } & 7.4 & 298 & 15.56 & 3.71 & 20.24 & 55.50 \\
\hline & & 333 & 19.22 & 5.90 & 20.73 & 50.36 \\
\hline & 2.0 & 298 & 19.69 & 0.84 & 18.64 & 57.16 \\
\hline & & 333 & 24.18 & 2.63 & 21.05 & 47.87 \\
\hline
\end{tabular}

\subsection{The Independent Gradient Model Analysis}

Figure 7 shows the gradient isosurface and scatter plot of the complex. In the gradient isosurface plot, the green region shows van der Waals force, which accounts for most of the area. The red region shows repulsion effect, which is mainly located near the benzene ring. The blue region shows hydrogen bond, which is mainly located near carbonyl oxygen, methyl oxygen, and phenolic hydroxyl oxygen. In the scatter plot, $\rho$ stands for the total electron density, $\lambda_{2}$ stands for the sign of the second eigenvalue of the electron density hessian [27], $\delta_{\mathrm{g}}$ is the local descriptor which reflects the interaction region between two (or more) fragments [28]. The green, blue and red represented van der Waals force, hydrogen bond and repulsion effect, respectively. The large peak observed in the range of $-0.02 \leq \operatorname{sign}\left(\lambda_{2}\right) \rho \leq 0.02$, indicating that there were many van der Waals interaction in the complex. Some points presented at $\operatorname{sign}\left(\lambda_{2}\right) \rho$ in the range of -0.05 to -0.02 demonstrated the presence of hydrogen bond, which was beneficial to stabilize the complex. However, $\operatorname{sign}\left(\lambda_{2}\right) \rho$ from 0.02 to 0.05 represented the presence of repulsion effect, which was not beneficial to stabilize the complex. In addition, at the same $\mathrm{pH}$, the number of points in $\operatorname{sign}\left(\lambda_{2}\right) \rho$ ranging from -0.05 to -0.02 increased as temperature increased. This suggested that the number of hydrogen bonds increased, which was consistent with changed in the number of hydrogen bonds in MD simulation (Figure 6).
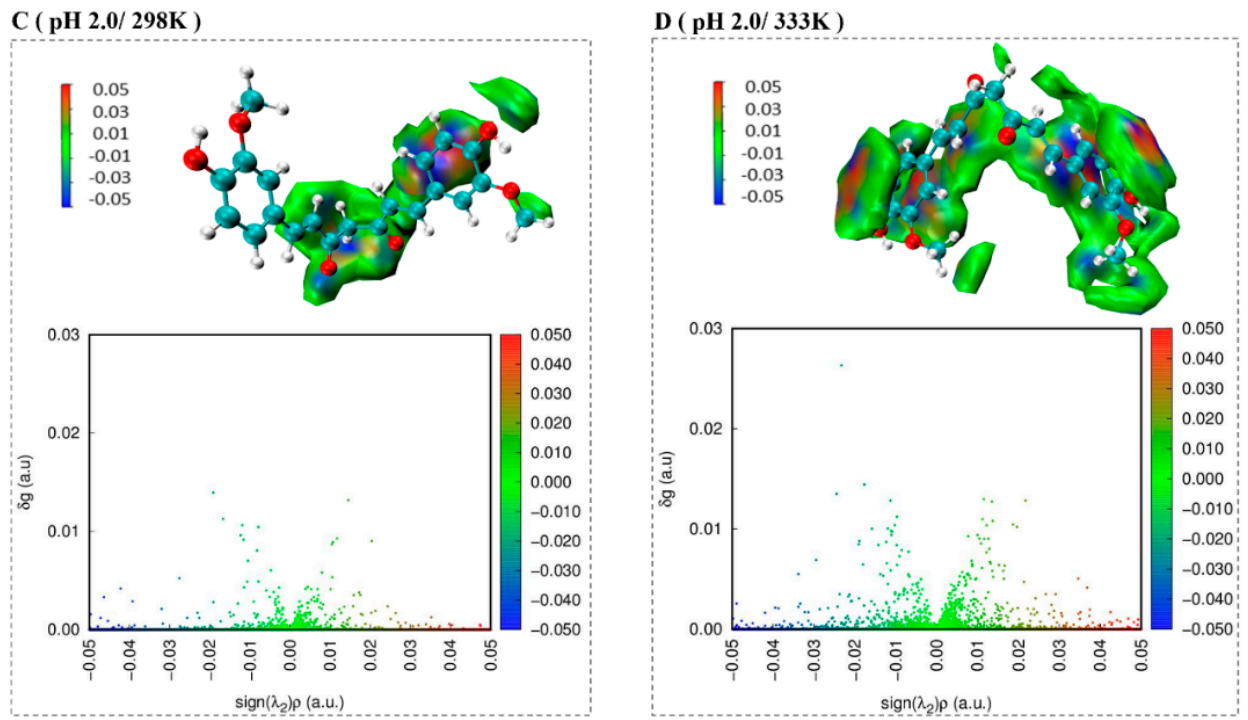

Figure 7. Cont. 

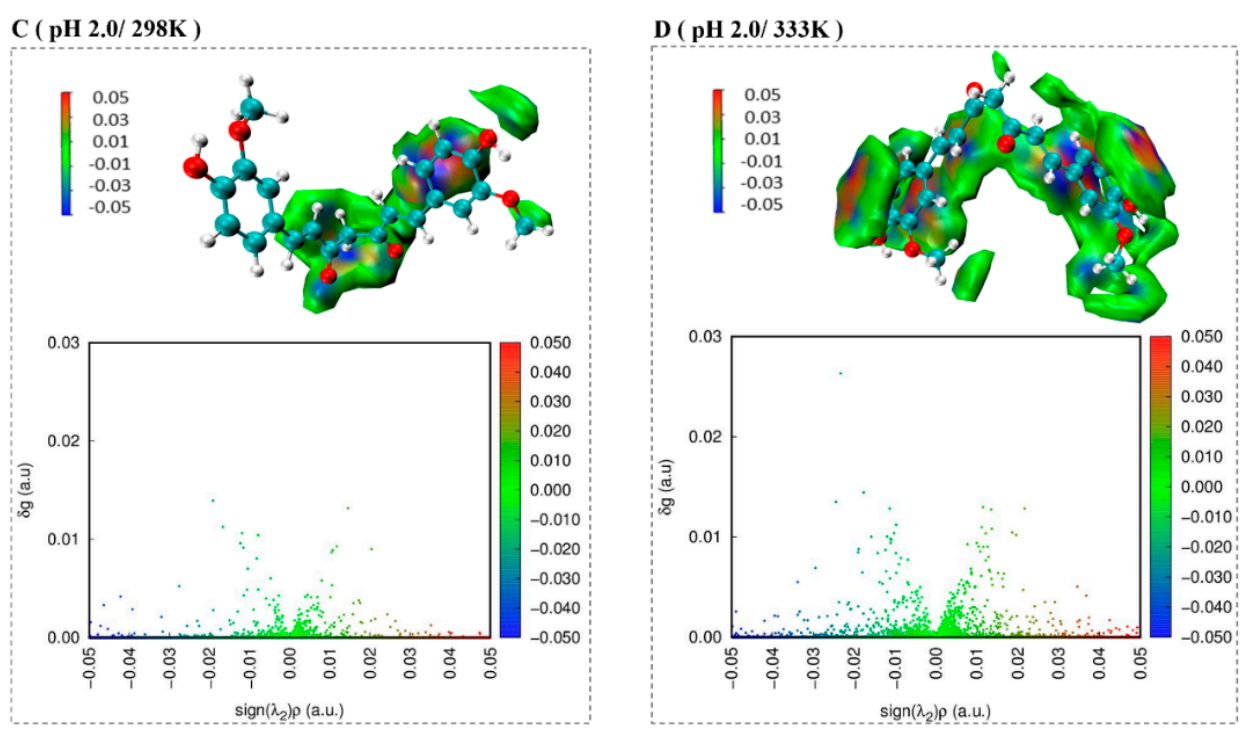

Figure 7. Gradient isosurface and scatter plot of the complex under different $\mathrm{pH}$ values and temperatures.

\section{Materials and Methods}

\subsection{Materials}

Casein (CAS\#: 9000-71-9) was purchased from Hefei Bomei Biotechnology Co., Ltd., Room 901, Office B-Xinghua International Plaza, No. 50, Hetang Road, Luyang District, Hefei, China. Curcumin (CAS\#: 458-37-7, purity $\geq 95 \%$ ) was obtained from Sinopharm Chemical Reagent Co., Ltd., No. 52, Ningbo Road, Shanghai, China. Absolute ethanol (CAS\#: 64-17-5) and hydrochloric acid (CAS\#: 7647-01-0) were purchased from Chongqing Chuandong Chemical (Group) Co., Ltd., No. 70, Danzishi New Street, Danzishi Street, Nan'an District, Chongqing, China. Tris (CAS\#: 77-86-1) was supplied from Saiguo Biotech Co., Ltd., No. 1, Eighth Alley, Zhangmu Mountain, Cen Village, Guangzhou, Tianhe District, Guangzhou, China. All reagents used in the experiments were analytical grade, and ultrapure water was used for the experiments.

\subsection{Methods}

\subsubsection{Solution Preparation}

$0.2 \mathrm{~g}$ of casein powder was dissolved in $0.05 \mathrm{~mol} / \mathrm{L}$ Tris- $\mathrm{HCl}$ buffer with $\mathrm{pH}$ of 7.4 and 2.0. The solvent was filled up to $100 \mathrm{~mL}$ after the casein had fully dissolved to obtain a $2 \mathrm{~g} / \mathrm{L}$ casein solution. $0.0368 \mathrm{~g}$ curcumin was dissolved in anhydrous ethanol, and the solvent filled up to $1000 \mathrm{~mL}$ to obtain a $1.0 \times 10^{-4} \mathrm{~mol} / \mathrm{L}$ curcumin solution.

\subsubsection{Fluorescence Spectroscopy}

The fluorescence spectra were recorded by a fluorescence spectrophotometer (F-2500, Hitachi Limited, Tokyo, Japan). Casein solution (1 mL) was added to each centrifuge tube, then different volumes of curcumin solutions were added to obtain curcumin concentrations of $0 \times 10^{-6}, 2 \times 10^{-6}, 4 \times 10^{-6}, 6 \times 10^{-6}, 8 \times 10^{-6}$, and $10 \times 10^{-6} \mathrm{~mol} / \mathrm{L}$. Tris- $\mathrm{HCl}$ buffer was added to set the volume to $10 \mathrm{~mL}$. The tubes were oscillated to mix evenly. Three sample groups were prepared and incubated in a thermostatic water bath at 298, 305 and $312 \mathrm{~K}$ for $30 \mathrm{~min}$. The excitation wavelength was $280 \mathrm{~nm}$, and the excitation spectra of the samples were scanned with an emission wavelength in the range of 300-450 nm.

Fluorescence quenching of casein by curcumin and binding parameters of curcumin to casein can be calculated from the results of fluorescence spectroscopy. The quenching rate constants and quenching constants were analyzed using the Stern-Volmer equation (Equation (1)) [29]:

$$
\frac{F_{0}}{F}=1+K_{s v}[Q]=1+K_{q} \tau_{0}[Q]
$$


where $F$ and $F_{0}$ are endogenous fluorescence intensities of casein with and without curcumin; $K_{q}$ is the quenching rate constant; $K_{s v}$ is the quenching constant; $[Q]$ is the curcumin concentration; and $\tau_{0}$ is the biomolecular fluorescence life time in the absence of quencher being equal to $10^{-8} \mathrm{~s}$.

The binding sites and binding constants of curcumin to casein were analyzed by using Equation (2) [30]:

$$
\log \left(\frac{F_{0}-F}{F}\right)=\log K_{b}+n \log [Q]
$$

where $F_{0}, F$, and $[Q]$ are the same as the Stern-Volmer equation; $K_{b}$ is the binding constant, and $n$ is the number of binding sites.

Thermodynamic parameters were calculated using the thermodynamics equation [31] (Equations (3) and (4)):

$$
\begin{aligned}
\ln K_{b} & =-\frac{\Delta H}{R T}+\frac{\Delta S}{R} \\
\Delta G & =\Delta H-T \Delta S
\end{aligned}
$$

where $K_{b}$ is the binding constant, $T$ is the experimental temperature, $\Delta H$ is the change in enthalpy, $\Delta G$ is the change in free energy, $\Delta S$ is entropy change and $R$ is the gas constant $(8.314 \mathrm{~J} /(\mathrm{mol} \cdot \mathrm{K}))$.

\subsubsection{Ultraviolet-Visible Spectroscopy}

Measurements were carried out at $298 \mathrm{~K}$ by using ultraviolet-visible spectrophotometer (Beijing General Analytical Instrument Limited Company, TU-1950, Beijing, China). Casein solution $(1 \mathrm{~mL})$ was added to each centrifuge tube, then different volumes of curcumin solutions were added to obtain curcumin concentrations of $0 \times 10^{-6}, 2 \times 10^{-6}$, $4 \times 10^{-6}, 6 \times 10^{-6}, 8 \times 10^{-6}$, and $10 \times 10^{-6} \mathrm{~mol} / \mathrm{L}$. Tris- $\mathrm{HCl}$ buffer was added to set the volume to $10 \mathrm{~mL}$. The tubes were oscillated to mix evenly. The samples were placed at $298 \mathrm{~K}$ for $20 \mathrm{~min}$. The samples were scanned from 190 to $450 \mathrm{~nm}$.

\subsection{4. $\beta$-Casein Homology Modeling}

As the three-dimensional crystallization structure of $\beta$-casein had not been obtained, homology modeling was used to construct its three-dimensional structure. First, the UniProt database (https://www.uniprot.org/ (accessed on 12 March 2021)) was used to search for the sequence information of $\beta$-casein (P09116). After local alignment, a search was performed at the RCSB protein database. After comparison, the structures with PDB ID of 5TC1, 2Q2F, and $6 \mathrm{O} 35$ were selected as mixed templates. Then, MODELLER (v.9.22) was used for modeling to obtain the optimal three-dimensional conformation. The PROCHECK [32,33] program (https: / / servicesn.mbi.ucla.edu/PROCHECK/ (accessed on 16 March 2021)) was used to validate and evaluate the three-dimensional protein model.

\subsubsection{Molecular Docking}

The preliminary three-dimensional structure of curcumin was obtained from Pubchem Compound (https:/ / pubchem.ncbi.nlm.nih.gov (accessed on 17 March 2021)) in NCBI (Pubchem CID: 969516). The structure of $\beta$-casein was obtained from the aforementioned homology modeling. YASARA [34] (v.20.10.4) was used for energy minimization to obtain preliminary optimized structures. The setting of different $\mathrm{pH}$ values ( $\mathrm{pH} 7.4$ and 2.0) was achieved by simulating the different protonation states of amino acid residues under the corresponding $\mathrm{pH}$ conditions. The $\beta$-casein-curcumin complex was used as the center and expanded $5.0 \AA$ in all directions to obtain a cube. Curcumin and $\beta$-casein were considered flexible and rigid during the 100docking runs process. The 100-docking runs process performed in triplicate under each $\mathrm{pH}$ condition. Furthermore, the conformation with the lowest energy was selected as the docking result. PyMol (v.2.4.0a0) and LigPlot (v.2.2) was used to plot stable three-dimensional and two-dimensional images with the lowest energy and analyzed the interactions between curcumin and $\beta$-casein. 


\subsubsection{Simulation}

YASARA was used for MD simulation and Visual Molecular Dynamics [35] (v.1.9.3) was used for visualization analysis. AutoSMILES utility [36] involved in YASARA optimized the structure of the curcumin, generated a topology file and a structure file, and assigned AM1BCC charge to the atom in the topology file. The bond types were assigned by the general AMBER force field. The AMBER14 force field was used for $\beta$-casein. Before the simulation, periodic boundary conditions were employed. The lowest energy conformations obtained by three replicates of docking experiments were used as the initial conformations for MD simulation. Firstly, the corresponding $\mathrm{pH}$ and temperature ( $298 \mathrm{~K}$ and $\mathrm{pH} 7.4,333 \mathrm{~K}$ and $\mathrm{pH} 7.4,298 \mathrm{~K}$ and $\mathrm{pH}$ 2.0, and $333 \mathrm{~K}$ and pH 2.0) was set. Secondly, the docked $\beta$-casein-curcumin complex was used as the center, and an expansion of $10 \AA$ in all directions was performed to construct a cube. Then, TIP3P water molecules were added to fill before sodium ions $\left(\mathrm{Na}^{+}\right)$or chloride ions $\left(\mathrm{Cl}^{-}\right)$ions was added to neutralize the system charge. Finally, after energy minimization of the system, 60 ns MD simulation was performed. The MD simulation was carried out with a 2 fs time step, and energy and trajectory coordinates were recorded every $20 \mathrm{ps}$. After the $60 \mathrm{~ns}$ simulation was completed, the md_analyze tool in YASARA was used to analyze changes in root mean square deviation (RMSD), hydrogen bond, system energy and secondary structure with time.

\subsubsection{Weak Interaction Analysis}

The independent gradient model [37] was used to study the interactions between curcumin and $\beta$-casein. Based on the MD simulation results, one steady-state frame in the last $10 \mathrm{~ns}$ was selected for weak interaction analysis. The Multiwfn (v.3.7) program [38] was used to calculate the independent gradient model before Visual Molecular Dynamics was used for visualization analysis.

\subsubsection{Statistical Analysis}

All experiments were performed in triplicate. Data were shown as mean \pm standard deviation. The significance of the difference between the measured means was assessed using one-way analysis of variance with Turkey test at the 0.05 probability level in the SPSS software (version 14.0 demo; SPSS Inc., Chicago, IL, USA).

\section{Conclusions}

The interactions between curcumin and $\beta$-casein at different temperatures and $\mathrm{pH}$ values were illustrated by employing fluorescence, ultraviolet-visible spectroscopy, and MD simulation. The $K_{q}$ values under different conditions were greater than the maximum diffusion collision quenching constant $\left(2.0 \times 10^{10} \mathrm{~L} /(\mathrm{mol} \cdot \mathrm{s})\right)$, showing that the intrinsic fluorescence of casein was quenched by curcumin through static quenching mechanism. The binding of curcumin to casein was mainly driven by electrostatic interaction, as evidenced by negative values of $\Delta H$ and positive values of $\Delta S$. The binding energy of $\beta$-casein-curcumin complex $(-131.07 \mathrm{~kJ} / \mathrm{mol})$ was lower at $\mathrm{pH} 2.0$ and $298 \mathrm{~K}$ among four conditions, indicating that $\beta$-casein-curcumin complex was relatively stable at $\mathrm{pH} 2.0$ and $298 \mathrm{~K}$. This study preliminarily elucidated the interactions between curcumin and $\beta$-casein, which could provide a theoretical basis for expanding the application of curcumin-rich casein foods in the food industry.

Author Contributions: Conceptualization, J.Z.; methodology, R.Z.; writing —original draft preparation, R.Z.; writing — review and editing, X.Q. and J.Z.; analyzing the data, R.Z. and X.Q.; visualization, R.Z.; supervision, J.Z.; project administration, J.Z. All authors have read and agreed to the published version of the manuscript.

Funding: This work was supported by the Fundamental Research Funds for the Central Universities (No. XDJK2019B056), Venture \& Innovation Support Program for Chongqing Overseas Returnees (No. cx2018098) and Chongqing Municipal Training Program of Innovation and Entrepreneurship for Undergraduates (No. S202010635165). 
Institutional Review Board Statement: Not applicable.

Informed Consent Statement: Not applicable.

Data Availability Statement: Not applicable.

Conflicts of Interest: The authors declare no conflict of interest.

Sample Availability: Not available.

\section{References}

1. Fu, Y.S.; Chen, T.H.; Weng, L.B.; Huang, L.Y.; Lai, D.; Weng, C.F. Pharmacological Properties and Underlying Mechanisms of Curcumin and Prospects in Medicinal Potential. Biomed. Pharmacother. 2021, 141, 111888. [CrossRef] [PubMed]

2. Gupta, S.C.; Prasad, S.; Kim, J.H.; Patchva, S.; Webb, L.J.; Priyadarsini, I.K.; Aggarwal, B.B. Multitargeting by Curcumin as Revealed by Molecular Interaction Studies. Cheminform 2011, 28, 1937-1955. [CrossRef] [PubMed]

3. Cao, J.; Wang, T.; Wang, M. Investigation of the Anti-Cataractogenic Mechanisms of Curcumin through in vivo and in vitro Studies. BMC Ophthalmol. 2018, 18, 48. [CrossRef]

4. Ashry, A.M.; Hassan, A.M.; Habiba, M.M.; Elzayat, A.; Elsharnouby, M.E.; Sewilam, H.; Dawood, M.A.O. The Impact of Dietary Curcumin on the Growth Performance, Intestinal Antibacterial Capacity, and Haemato-Biochemical Parameters of Gilthead Seabream (Sparus aurata). Animals 2021, 11, 1779. [CrossRef] [PubMed]

5. Sandhiutami, N.M.D.; Arozal, W.; Louisa, M.; Rahmat, D.; Wuyung, P.E. Curcumin Nanoparticle Enhances the Anticancer Effect of Cisplatin by Inhibiting PI3K/AKT and JAK/STAT3 Pathway in Rat Ovarian Carcinoma Induced by DMBA. Front. Pharmacol. 2021, 11, 2199. [CrossRef] [PubMed]

6. Iova, G.M.; Calniceanu, H.; Popa, A.; Szuhanek, C.A.; Marcu, O.; Ciavoi, G.; Scrobota, I. The Antioxidant Effect of Curcumin and Rutin on Oxidative Stress Biomarkers in Experimentally Induced Periodontitis in Hyperglycemic Wistar Rats. Molecules 2021, 26, 1332. [CrossRef]

7. Ma, Z.W.; Wang, N.; He, H.B.; Tang, X. Pharmaceutical Strategies of Improving Oral Systemic Bioavailability of Curcumin for Clinical Application. J. Control. Release 2019, 316, 359-380. [CrossRef]

8. Michele, D.C.; Riccardo, G. Dietary Curcumin: Correlation between Bioavailability and Health Potential. Nutrients 2019, 11, 2147. [CrossRef]

9. $\quad$ Esmaili, M.; Ghaffari, S.M.; Moosavi-Movahedi, Z.; Atri, M.S.; Sharifizadeh, A.; Farhadi, M.; Yousefi, R.; Chobert, J.M.; Haertlé, T.; Moosavi-Movahedi, A.A. Beta Casein-Micelle as a Nano Vehicle for Solubility Enhancement of Curcumin; Food Industry Application. LWT-Food Sci. Technol. 2011, 44, 2166-2172. [CrossRef]

10. Zhang, L.; Wang, P.; Yang, Z.Y.; Du, F.F.; Li, Z.; Wu, C.L.; Fang, A.H.; Xu, X.L.; Zhou, G.H. Molecular Dynamics Simulation Exploration of the Interaction between Curcumin and Myosin Combined with the Results of Spectroscopy Techniques. Food Hydrocoll. 2020, 101, 105455. [CrossRef]

11. Rajabi, M.; Farhadian, S.; Shareghi, B.; Asgharzadeh, S.; Momeni, L. Noncovalent Interactions of Bovine Trypsin with Curcumin and Effect on Stability, Structure, and Function. Colloids Surf. B 2019, 183, 110287. [CrossRef]

12. Wang, R.J.; Wei, Y.Y.; Wang, M.Q. Interaction of Natural Compounds in Licorice and Turmeric with HIV-NCp7 Zinc Finger Domain: Potential Relevance to the Mechanism of Antiviral Activity. Molecules 2021, 26, 3563. [CrossRef]

13. Allahdad, Z.; Varidi, M.; Zadmard, R.; Saboury, A.A.; Haertlé, T. Binding of $\beta$-Carotene to Whey Proteins: Multi-Spectroscopic Techniques and Docking Studies. Food Chem. 2018, 277, 96-106. [CrossRef]

14. Saleh, T.; Soudi, T.; Shojaosadati, S.A. Redox Responsive Curcumin-Loaded Human Serum Albumin Nanoparticles: Preparation, Characterization and in vitro Evaluation. Int. J. Biol. Macromol. 2018, 114, 759-766. [CrossRef]

15. Safavi, M.S.; Shojaosadati, S.A.; Yang, H.G.; Kim, Y.J. Reducing Agent-Free Synthesis of Curcumin-Loaded Albumin Nanoparticles by Self-Assembly at Room Temperature. Int. J. Pharm. 2017, 529, 303-309. [CrossRef]

16. Mirpoor, S.F.; Hosseini, S.M.H.; Yousefi, G.H. Mixed Biopolymer Nanocomplexes Conferred Physicochemical Stability and Sustained Release Behavior to Introduced Curcumin. Food Hydrocoll. 2017, 71, 216-224. [CrossRef]

17. Chen, F.P.; Li, B.S.; Tang, C.H. Nanocomplexation between Curcumin and Soy Protein Isolate: Influence on Curcumin Stability/Bioaccessibility and in vitro Protein Digestibility. J. Agric. Food Chem. 2015, 63, 3559-3569. [CrossRef]

18. Wusigale; Liang, L.; Luo, Y.C. Casein and Pectin: Structures, Interactions, and Applications. Trends Food Sci. Technol. 2020, 97, 391-403. [CrossRef]

19. Zhang, M.; Lai, T.T.; Yao, M.K.; Zhang, M.; Yang, Z.N. Interaction of the Exopolysaccharide from Lactobacillus Plantarum YW11 with Casein and Bioactivities of the Polymer Complex. Foods 2021, 10, 1153. [CrossRef] [PubMed]

20. Qin, J.J.; Yang, M.; Wang, Y.C.; Wa, W.Q.; Zheng, J. Interaction between Caffeic Acid/Caffeic Acid Phenethyl Ester and Micellar Casein. Food Chem. 2021, 349, 129154. [CrossRef] [PubMed]

21. Cao, X.Y.; He, Y.L.; Kong, Y.C.; Mei, X.Y.; Huo, Y.P.; He, Y.; Liu, J.L. Elucidating the Interaction Mechanism of Eriocitrin with $\beta$-Casein by Multi-Spectroscopic and Molecular Simulation Methods. Food Hydrocoll. 2019, 94, 63-70. [CrossRef]

22. Valenti, L.; Riso, P.; Mazzocchi, A.; Porrini, M.; Fargion, S.; Agostoni, C.; Angeloni, C. Dietary Anthocyanins As Nutritional Therapy for Nonalcoholic Fatty Liver Disease. Oxid. Med. Cell. Longev. 2013, 2013, 145421-145428. [CrossRef] [PubMed] 
23. Wei, J.; Xu, D.X.; Yang, J.; Zhang, X.; Mu, T.; Wang, Q.Y. Analysis of the Interaction Mechanism of Anthocyanins (Aronia Melanocarpa Elliot) with $\beta$-Casein. Food Hydrocoll. 2018, 84, 276-281. [CrossRef]

24. Ross, P.D.; Subramanian, S. Thermodynamics of Protein Association Reactions: Forces Contributing to Stability. Biochemistry 1981, 20, 3096-3102. [CrossRef]

25. Sun, Q.; He, J.; Yang, H.; Li, S.; Zhao, L.; Li, H. Analysis of Binding Properties and Interaction of Thiabendazole and Its Metabolite with Humanserum Albumin via Multiple Spectroscopic Methods. Food Chem. 2017, 233, 190-196. [CrossRef] [PubMed]

26. Brennan, J.D. Using Intrinsic Fluorescence to Investigate Proteins Entrapped in Sol-Gel Derived Materials. Appl. Spectrosc. 1999, 53, 106A-121A. [CrossRef]

27. Wieduwilt, E.K.; Boisson, J.C.; Terraneo, G.; Hénon, E.; Genoni, A. A Step toward the Quantification of Noncovalent Interactions in Large Biological Systems: The Independent Gradient Model-Extremely Localized Molecular Orbital Approach. J. Chem. Inf. Model. 2021, 61, 795-809. [CrossRef] [PubMed]

28. He, C.Y.; Liu, X.L.; Jiang, Z.J.; Geng, S.; Ma, H.J.; Liu, B.J. Interaction Mechanism of Flavonoids and $\alpha$-Glucosidase: Experimental and Molecular Modelling Studies. Foods 2019, 8, 355. [CrossRef]

29. Chung, C.; Rojanasasithara, T.; Mutilangi, W.; McClements, D.J. Enhancement of Colour Stability of Anthocyanins in Model Beverages by Gum Arabic Addition. Food Chem. 2016, 201, 14-22. [CrossRef]

30. Roy, S.; Nandi, R.K.; Ganai, S.; Majumdar, K.C.; Tapan, K.D. Binding Interaction of Phosphorus Heterocycles with Bovine Serum Albumin: A Biochemical Study. J. Pharm. Anal. 2017, 7, 19-26. [CrossRef]

31. Jang, J.C.; Liu, H.; Chen, W.; Zou, G.L. Binding of Mitomycin C to Blood Proteins: A Spectroscopic Analysis and Molecular Docking. J. Mol. Struct. 2009, 928, 72-77. [CrossRef]

32. Laskowski, R.A.; MacArthur, M.W.; Moss, D.S.; Thornton, J.M. PROCHECK: A Program to Check the Stereochemical Quality of Protein Structures. J. Appl. Crystallogr. 1993, 26, 283-291. [CrossRef]

33. Laskowski, R.A.; Rullmann, J.A.C.; Macarthur, M.W.; Kaptein, R.; Thornton, J.M. QUA and PROCHECK-NMR: Programs for Checking the Quality of Protein Structures Solved by NMR. J. Biomol. NMR 1996, 8, 477-486. [CrossRef] [PubMed]

34. Elmar, K.; Gert, V. YASARA View-Molecular Graphics for All Devices-from Smartphones to Workstations. Bioinformatics 2014, 20, 2981-2982. [CrossRef]

35. Humphrey, W.; Dalke, A.; Schulten, K. VMD: Visual Molecular Dynamics. J. Mol. Graph. 1996, 14, 33-38. [CrossRef]

36. Jakalian, A.; Jack, D.B.; Bayly, C.I. Fast, Efficient Generation of High-quality Atomic Charges. AM1-BCC Model: II. Parameterization and Validation. J. Comput. Chem. 2002, 23, 1623-1641. [CrossRef]

37. Corentin, L.; Gaëtan, R.; Hassan, K.; Jean-Charles, B.; Julia, C.G.; Eric, H. Accurately Extracting the Signature of Intermolecular Interactions Present in the NCI Plot of the Reduced Density Gradient versus Electron Density. Phys. Chem. Chem. Phys. 2017, 19, 17928-17936. [CrossRef]

38. Lu, T.; Chen, F.W. Multiwfn: A Multifunctional Wavefunction Analyzer. J. Comput. Chem. 2012, 33, 580-592. [CrossRef] 